\title{
Reflection of Entrepreneurial Requirements in the Database Systems Instruction
}

\author{
Petra Poulova Ivana Simonova \\ University of Hradec Kralove, Faculty of Informatics and Management
}

\begin{abstract}
This paper describes approaches to reflecting entrepreneurial requirements in methods and tools applied in the Database Systems (DBS) instruction at the University of Hradec Kralove. Resulting from numerous discussions with partners, the theoretical issues in DBS courses are followed by practical training. Thus the learners have possibility to study both the theory and work with practical database products ORACLE, MS SQL, DB2 a MySQL using them in project work within the DBS courses. They co-operate in teams on developing an operating database application for a real (or virtual) organization.
\end{abstract}

Keywords: Computer Science Education; Databases; Multimedia; Internet; Educational Software; Web-Based Education

\section{Introduction}

Currently, databases have become an integral part of computer applications. Despite they are invisible to the users, applications cannot run without them. The Computer Science study programme graduates are expected to be wellprepared in this field - companies expect them to have both theoretical knowledge and practical experience in this field. At the Faculty of Informatics and management (FIM), University of Hradec Kralove (UHK) the Database Systems (DBS) courses 1 and 2 are included in the curriculum of the master study programme of Information Management and bachelor study programme of Applied Informatics. Several years ago the university became a member of HIT cluster (Hradec IT cluster). The cluster is a regional association joining regional IT companies and the FIM.

The co-operation is held in various forms. Besides solving the practical research problems in bachelor, diploma and dissertation theses and joint projects, where both students and teachers are involved, invited speakers from companies read papers on latest trends in the field, provide contacts to work programmes abroad, have possibility to influence the learning content of the DBS courses to real requirements and de-fine the graduate profile. The Database Technology group was set within the HIT cluster to adjust the concept of learning content to practical requirements.

\section{Content of DBS Courses}

The matter of database systems has been introduced in various subjects, e.g. Object Oriented Modeling, Programming etc. The basic curriculum consists of DBS1 and DBS2 courses in the bachelor study programme, and Distributed and object-relational databases (DORDB) and 
Modern Information Systems (MOIS) in the master study programmes.

All courses are divided in one or two hours lectures per week, two hours of tutorials per week and two hour of students' independent work. Lectures are devoted to theory and introducing practical examples; other examples are provided within tutorials. The project work is applied within all subjects.

The DBS1 course students work on two projects. The first one deals with the data modeling and creating databases, the second one focuses on work with data SQL queries, triggers and views. Students can decide whether they prefer practicing in ORACLE or MS SQL Server.

The DBS2 course gives students possibility to work in groups. The project objective is to develop an operating database application for a real (or virtual) organization as small businesses. Students should go through all stages of the database development - the analysis, conceptual, logical and physical design. Students can choose one or more of four 4-hour elective workshops aiming at deepening their knowledge in technology MS SQL and .NET, ORACLE and APEX, MySQL and PHP, or DB2 and JAVA.

The MOIS and DORDB courses provide students with possibility to participate in the development of real-life application.

\section{Practical Approach}

In all the database courses strong attention is paid to practical training, which is emphasized by the HIT cluster members.

Project work offers a number of benefits to students, e.g. it is the best way to expose student to applications of the database design cycle and its use in practice. These include interaction with users, extracting requirements from users who do not have a clear conception what they require, and prototyping. Students go through all stages of database development - analysis, conceptual, logical and physical design. The project also teaches students the benefits of prototyping and user feedback. And, it develops the skill of team work. Teams usually consist of three-four members (fewer than three members is not useful, there would be much work for each member, and the group of more than five members is difficult to coordinate). Each team should have members with complementary skills such as communication and leadership, knowledge of algorithmization, programming and data modeling.

\section{4. eLearning and Database Systems}

eLearning courses are understood standard in higher education. [1] It has become of common level for more than 15 years that the university course was supported by the web-based education at the Faculty of Informatics and Management.

eLearning courses provide numerous advantages to the learners and tutors. From the learner's point of view the accessibility of study materials anytime anywhere is the most appreciated feature, followed by financial savings in commuting expenses. [2], [3] Tutors emphasize efficient and immediate feedback. eLearning provides advantages for institutions as well - the institutions can reach some financial savings. [4]

The process of instruction can be supported by various educational software; virtual learning environments based on Learning Management System (LMS) are often used [5]. At FIM online courses supporting the Database Systems instruction are created in the LMS Blackboard. 


\section{Monitoring Students' Knowledge and Attitudes}

The process of ICT-supported instruction has become the objective of research activities. Both the cognitive and affective processes are monitored. After each academic year the pedagogical experiment run to compare students' knowledge formed in the traditional (face-to-face) form or in the ICTsupported process of instruction. The received results show that students reach the same level of knowledge in both ways of instruction [6], [7].

A survey and interview were used to get information on students' attitudes towards the content and form of instruction. This research ran repeatedly in 2005, 2009 and 2012 academic years. Questions included in the questionnaire were created on the basis of analysis of previous interviews with students. The questionnaire comprised close and semiclose questions, and a few open questions. The most important results are presented below. First, students expectations of the learning content were monitored (Figure 1). The highest rate of satisfaction was detected in 2012.

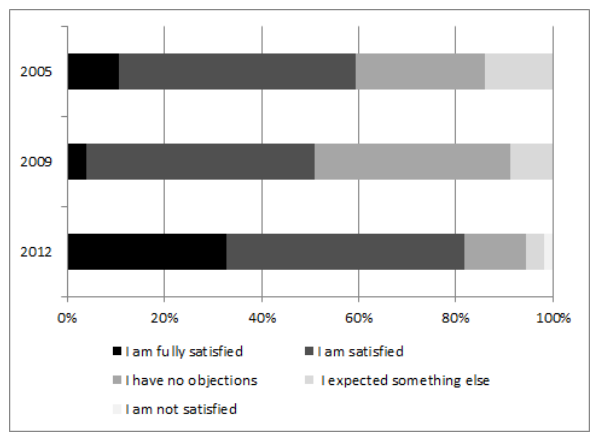

Fig. 1. "Did the content of the subject DBS meet your expectations?"

Students also evaluated the extent and content of the subject on the 5-level scale, i.e. how much they learned: I consider the content (1) too large - (2) large - (3) adequate - (4) insufficient - (5) totally insufficient (Figure 2). The results of evaluation do not show any significant tendencies in single years, more than $2 / 3$ of respondents consider the learning content adequate to their needs.

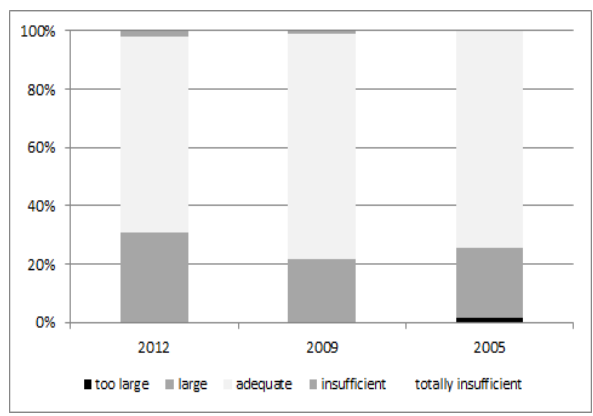

Fig. 2. Evaluation of the content and extent of the course

Students also dealt with the number of hours which they devoted to preparation and study in the course, particularly number of hours devoted to the work on project and autonomous study of theoretical content. Figure 3 displays the average values necessary for studying.

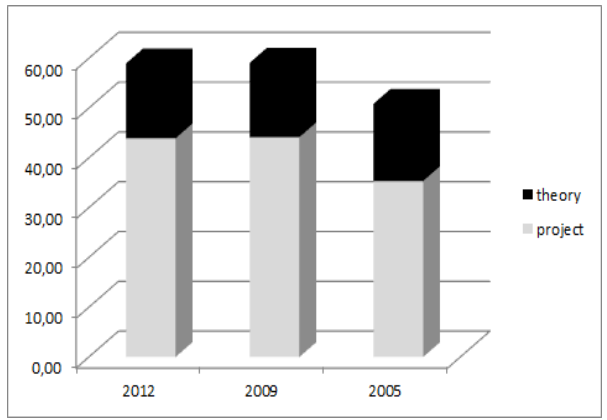

Fig. 3. Time spent on studying

Single data show that students devoted more time working on project (12-230 hours) than they spent on preparation for the examination (1-80 hours). The project work covers approximately $3 / 4$ of the whole time devoted to the subject. This extent has increased lately when the learning content closely relates to practical requirements. 


\section{Conclusion}

Databases as an integral part of current computer applications are of great importance, and they are included in curricula of the Computer Science Education.

Both the theoretical knowledge and practical skills of students are highly required. In the time of information society eLearning courses supporting the process of instruction are often used.

The theoretical learning content should be reflected in the practical knowledge and experience. As the above described research shows this approach positively influences not only the employment rate of graduates and satisfaction of their potential employers but it is also appreciated by students.

\section{Acknowledgement}

This paper is supported by the Excellence Project N. 2216.

\section{References}

[1] Balogh, Z., Turčáni, M., Burianová, M. Modelling web-based educational activities within the combined forms of education with the support of applied informatics with. Proceeding of the 7th International Conference Efficiency and Responsibility in Education 2010. Praha : Czech University of Life Sciences, 2010. pp. 14-24.

[2] Kapusta, J., Munk, M., Turčáni, M. Experimental comparison of adaptive links annotation technique with adaptive direct guidance technique. Webist 2009: ACM Conference Proceedings. 5th International Conference on Web Information Systems and Technologies, Lisabon : Instic Press, 2009. pp. 250-256.

[3] Šimonová, I., Poulová, P., Bílek, M. Students' communication in on-line courses. Proceedings of the 6th WSEAS/IASME International Conference on Educational Technologies (EDUTE'10). Kantaoui, WSEAS Press, 2010, pp. 87 - 93.

[4] Šimonová, I., Poulová, P., Šabatová, M. et al. On contribution of modern technologies towards developing key competences. Hradec Králové: M. Vognar, 2009.

[5] Bri, D., Garcia, M., Coll, H., Lloret, J. A Study of Virtual Learning Environments, WSEAS Transactions on Advances in Engineering Education. Issue 1, Volume 6, 2009.

[6] Poulová, P., Černá, M. eLearning Demands from the Perspective of Students and their Attitudes towards It. EDUCON 2011 : IEEE second annual global engineering education conference. Piscataway : IEEE, 2011, pp. 745-750.

[7] Poulová, P., Maněnová, M. The role of eLearning in the development of university students' competences. Information and communication technology in education 2010 : international conference. Ostrava : Ostravská univerzita, 2010, pp. 145148. 